\title{
Ocular and visual defects in a geographically defined population of 2-year-old children
}

\author{
Maureen Stayte, Ann Johnson, Catherine Wortham
}

\begin{abstract}
Ocular and/or visual defects were diagnosed by age 2 years in $2 \cdot 1 \%$ of infants born in 1984 in one health district. Infants of low birth weight or infants requiring special care in the neonatal period had a two and a half times greater risk of vision and ocular defects than the remainder of the population. In particular, the rate of squint and neurological disease affecting the visual system was significantly greater in this high risk group than in the low risk group. The degree of visual impairment in the high risk group tended to be more severe than in the low risk group. Overall, however, the majority of children with vision or ocular defects $(85 \%)$ were in the low risk group.
\end{abstract}

With falling perinatal mortality the numbers of infants of low birth weight who survive the perinatal period are increasing. ${ }^{1}$ These infants are known to be at increased risk of ocular and vision defects. ${ }^{23}$ There is concern that they may be contributing unduly to pre-school vision impairment within the community. While Blind and Partially Sighted Registration is one source of severe visual impairment data, the information is often incomplete by 2 years of age and does not include all types of visual and ocular defects.

In order to look at this problem we have ascertained the outcome of referrals of infants from birth to 2 years to the hospital eye service in a geographically defined population. The numbers of referred infants who were of low birth weight or who had required special care in the neonatal period were compared with the number of referrals from the remainder of the population. The characteristics of the ocular and vision defects diagnosed in the two populations are described.

\section{Materials and methods}

Information on all infants who were referred for an ophthalmological opinion by 2 years of age was obtained by searching eye clinic and orthoptic records within Oxfordshire Health District. This was a manual search; only the Blind and Partially Sighted Registers were on a computerised system. It involved searching all hospital index files, hospital notes, and registers of new patients attending orthoptic departments within the Oxfordshire health district. Casualty records were excluded. Additional information was obtained from the paediatric assessment centres, from Special Needs Advisers to the Department of Education, Department of Social Services who held the 'Blind Register', Eye Operation Register, and the Birth Registers.

The following information was abstracted from the records: (a) Health district of birth; $(b)$ birth weight; $(c)$ whether admitted to special care nursery; $(d)$ age at referral; $(e)$ outcome of referral.

A case was defined as a child with a recognised or suspected ocular or visual abnormality requiring treatment or surveillance. Cases were classified as shown in Table I. Children with

TABLE I Numbers of children with diagnosed ocular and vision defects at age 2 years

Oxford Eye Hospital, Walton Street, Oxford OX2 6AN

M Stayte

C Wortham

Oxford Region Child

Development Project

A Johnson

Correspondence to:

Mrs M Stayte.

Accepted for publication

15 February 1990

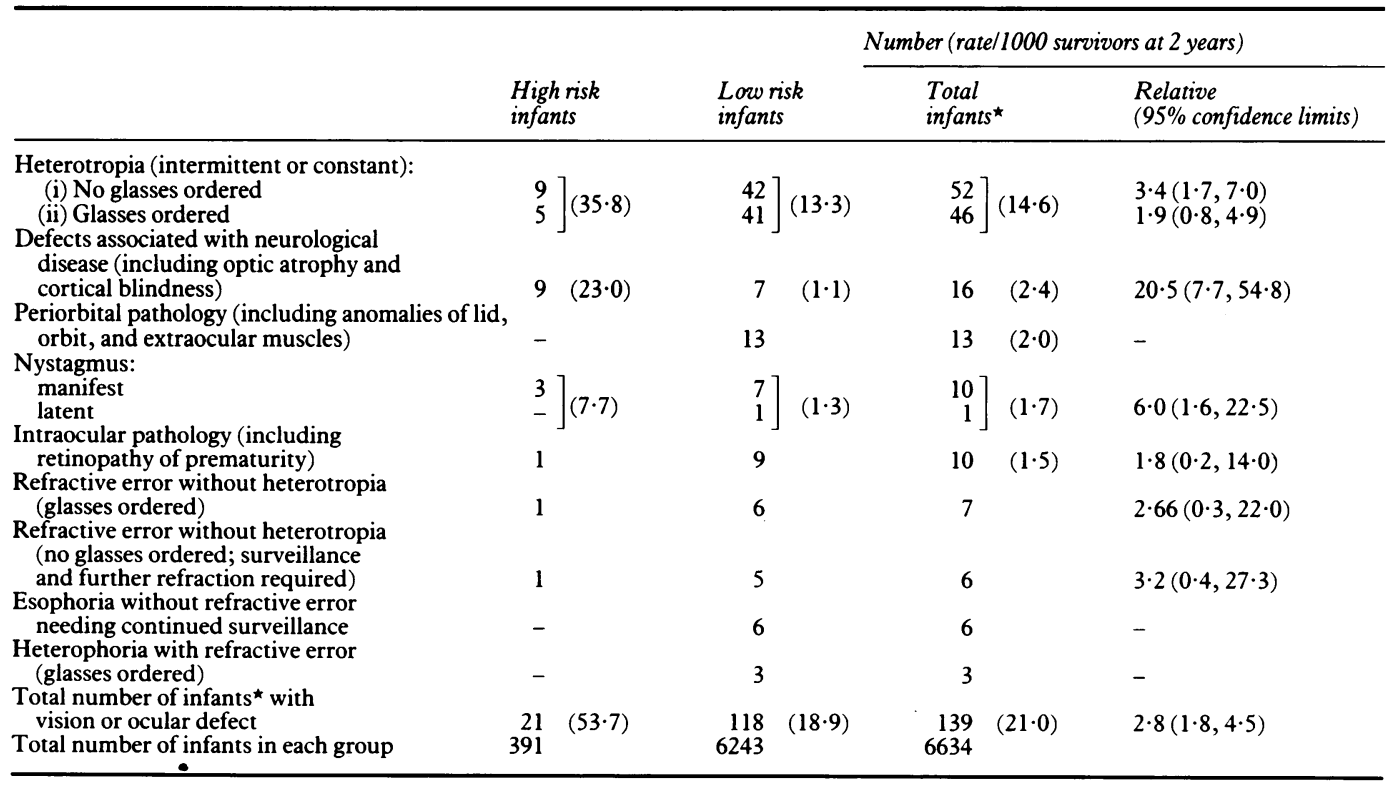

^Some infants have more than one defect. 
blocked tear ducts and conjunctivitis were excluded.

The total population under study was divided into two groups:

(1) Infants born in 1984 to mothers resident in the Oxford health district at the time of birth, who were either less than $2000 \mathrm{~g}$ birth weight or who were $2000 \mathrm{~g}$ or more at birth and requiring admission to a special care nursery for longer than 24 hours were termed 'high risk'. These infants were identified as part of the Oxford Region Child Development Project ${ }^{4}$ and were considered at increased risk of ocular and vision defect.

(2) Infants born in 1984 who were $2000 \mathrm{~g}$ or more at birth and did not require any special care in the neonatal period were designated as 'low risk'. This group consisted of infants with these characteristics who were resident in the district at age 2 years. While not all may have been born to mothers resident in Oxfordshire at the time of birth, it was assumed that among this low risk population the population movement into the district was balanced by those leaving the district. ${ }^{5}$

Outcome information was sought on infants from the high risk group who were known to have left the district and to have been referred for an ophthalmological opinion to a centre outside the district. Infants who had moved into the district after birth, and were known to have been of low birth weight or requiring special care were not included in the study.

\section{Results}

In 1984 there were 6687 live births to mothers who were resident in the Oxford health district at the time of delivery. Fifty three infants had died by age 2 years: 33 died in the neonatal period, a further 18 before the age of 1 year and two infants died in their second year (Table II). Forty two of the 53 infants who died were in the high risk group and 11 were in the low risk group. The mortality rate in the high risk groups was 97/1000 live births compared with a mortality rate of $1 \cdot 8 / 1000$ live births in the low risk population.

Of the 6634 infants alive at age 2 years 252 $(3 \cdot 8 \%)$ had been referred for an ophthalmological opinion. One hundred and thirty nine of these were diagnosed as having an ocular or visual defect. Overall $2 \cdot 1 \%$ of the 2 -year-old population had a diagnosed ocular or visual impairment.

Of these infants (alive at age 2 years) 391 were in the high risk group and 6243 in the low risk group (Table III). Twenty one of the 391 high risk infants and 118 of the 6243 low risk infants had an ocular or vision problem by age 2 years. Although the risk of such impairment was significantly higher in the high risk group than in the low risk group (relative risk $=2 \cdot 8$ with $95 \%$ confidence limits of 1.8 to 4.5 ) (Fig 1 ), the high risk group contributed only $15 \%$ of all cases.

Overall the commonest defect was heterotropia, which was present in $70 \%$ of all children designated as cases (Table I). The types of heterotropia and heterophoria diagnosed by age 2 years are shown in Table IV. Approximately half the cases in each group had a constant
TABLE II Total number of infants in study

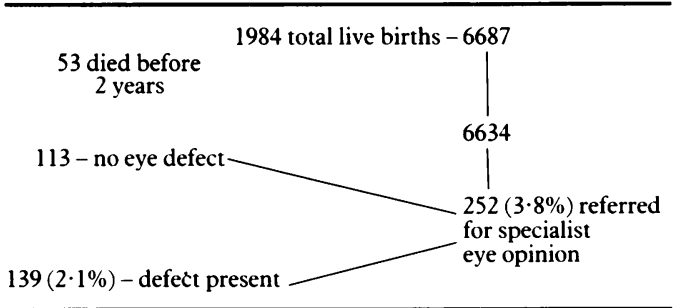

esotropia, whereas only two children had constant exotropia. Heterophoria was recorded only in the low risk group. The risk of heterotropia was significantly greater in the high risk group than in the low risk group (relative risk= $2 \cdot 7$ with $95 \%$ confidence limits of $1 \cdot 5$ to $4 \cdot 7$ ).

Ocular and visual defects associated with neurological disease accounted for $12 \%$ of all defects detected by age 2 years. Of the 16 infants in this category 11 had cerebral palsy. Six of these 11 children had a heterotropia. Many of the children with cerebral palsy had severe impairment of vision (three with optic atrophy and three with 'cortical blindness'). The relative risk of a vision/ocular defect associated with neurological disease in the high risk group of infants was $20 \cdot 5$ with confidence limits to $7 \cdot 7$ to $54 \cdot 8$.

Intraocular and periorbital pathology accounted for $17 \%$ of all cases, all but one of which were in the low risk group. The defects in the low risk group were lens opacities (2), congenital choroiditis (1), unilateral microphthalmos and coloboma (1), bilateral colobomata (1), correctopia (1), congenital toxoplasmosis (1), depigmented iris (1), cataract and retinal detachment secondary to trauma (1), unilateral ptosis (5), Marcus Gunn syndrome (2), Duane's syndrome ( $2 ; 1$ type A, 1 type B), Brown's syndrome (1), and inferior oblique overaction, with binocular single vision in the primary position (3).

There was a single case of grade IV retinopathy of prematurity in the high risk group, classified under intraocular pathology.

The range of refractive errors are shown in Figure 2, showing the eye with the highest refractive error. Astigmatism is in minus cylinders. Seventy one children $(51 \%$ of all children with an eye defect) had a recorded refractive error. Glasses were prescribed for 56 children. A further six children were not ordered glasses at this age but required further refractions and surveillance. No overall difference in the degree or type of refractive errors was found between the high risk and the low risk groups.

Ten of the 139 2-year-old children with an eye defect were blind or had very low vision. The

TABLE III Numbers of infants in high risk and low risk groups

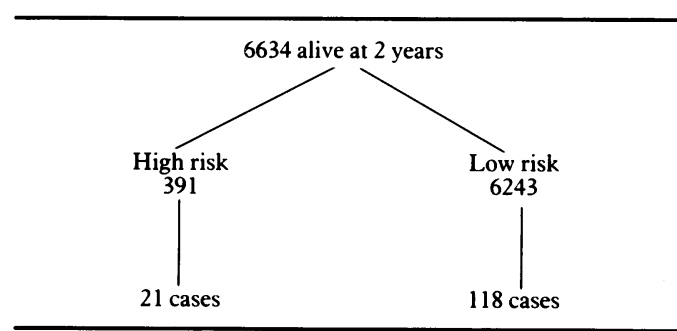


Vision/ocular defects in 2 yr old children

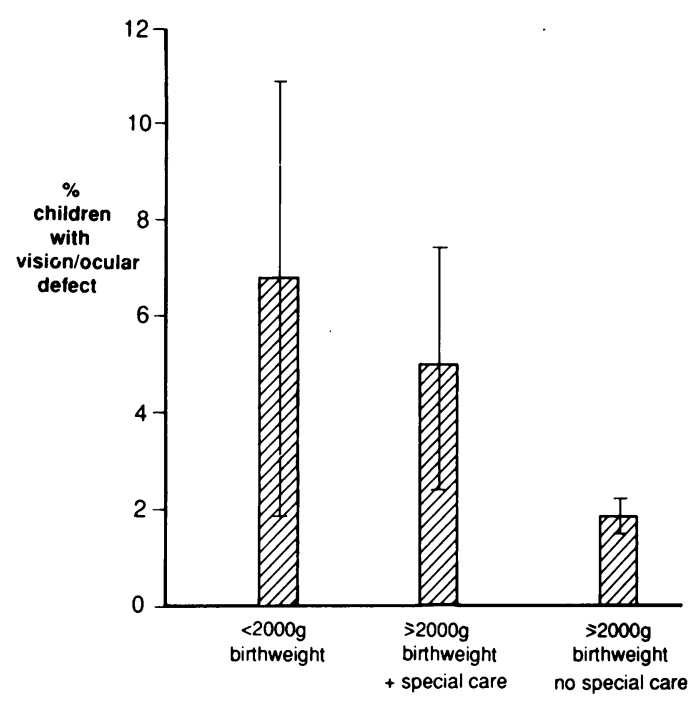

(with $95 \%$ confidence limits)

Figure 1: Vision and ocular defects in 2-year-old children by birth weight group and by admission to special care nursery.

underlying causes were cortical blindness (3), optic atrophy (3) (all these six children had cerebral palsy), retinopathy of prematurity (1), toxoplasmosis (1), optic nerve hypoplasia (1), and leucodystrophy (1).

The proportion of children with visual defects who appeared to have no useful vision or who will require low vision aids was considerably greater in the high risk group than the low risk group (six of 21 in the high risk group compared with four of 118 in the low risk group). The relative risk of severe impairment in the high risk group was 30.0 with $95 \%$ confidence limits of 6.8 to $84 \cdot 5$.

\section{Discussion}

By age 2 years $3 \cdot 8 \%$ of the infant population of a health district had been referred to a specialist eye service. A little over half of these referrals proved to fulfil the criteria of a case. Thus $2 \cdot 1 \%$ of the population had a diagnosed ocular or visual defect by age 2 years, Kendal $e$ al found $1.6 \%$ seen by 2 years, ${ }^{6}$ rising to $8.9 \%$ at age 6 years, and Kohler looked at 4-year-olds and found $8 \cdot 9 \% .^{7}$

The detailed search was unlikely to have missed cases referred within the health district.

TABLE IV Types of strabismus diagnosed by age 2 years

\begin{tabular}{lccc}
\hline & $\begin{array}{l}\text { Total } \\
\text { number } \\
\text { of cases }\end{array}$ & $\begin{array}{l}\text { High risk } \\
\text { infants }\end{array}$ & $\begin{array}{l}\text { Low risk } \\
\text { infants }\end{array}$ \\
\hline $\begin{array}{c}\text { Heterotropia } \\
\text { Constant: } \\
\text { convergent } \\
\text { divergent }\end{array}$ & 60 & 10 & 50 \\
$\begin{array}{c}\text { Intermittent: } \\
\text { divergent } \\
\text { convergent }\end{array}$ & 2 & 1 & 1 \\
Total & 22 & 2 & 20 \\
\hline $\begin{array}{l}\text { Heterophoria } \\
\text { Esophoria }\end{array}$ & 98 & 2 & 12 \\
$\begin{array}{l}\text { Exophoria } \\
\text { Total }\end{array}$ & 8 & 0 & 83 \\
\hline Total number of infants & 1 & 0 & 8 \\
in each group & 6634 & 391 & 6243 \\
\hline
\end{tabular}

However, population movement and uneven shifts of population could result in underestimates in the numbers of cases in the low risk population. Ascertainment was more likely to be complete in the high risk group, where there was a vigorous follow-up, including tracing infants who had moved outside the district. Underascertainment could also occur as a result of failure of cases to come to the attention of the ophthalmological services by age 2 years. This was again more likely to occur in the low risk group, where surveillance was less rigorous. However, despite this possible underestimate of the numbers of cases in the low risk group, $85 \%$ of all cases were from this section of the population.

We confirmed the previously described increase in risk of ocular and vision defects among low birth weight infants and infants requiring special care. ${ }^{28}$ In our series this high risk group had a higher rate of heterotropia, a higher prevalence of ocular and vision defects associated with neurological deficit, and a more severe level of visual loss.

The prevalence of heterotropia in the population studied was $1.5 \%$, comparable with $1.3 \%$ described by Friedman et $a l^{9}$; esotropia comprised $1.0 \%$ of cases. Few cases of heterophoria were detected. This could be because they cause little concern in this age group. Further study of this population may show a higher percentage of these cases. The small numbers of cases of intermittent esotropia may be due to the fact that the accommodative system is not fully functional in many children by 2 years of age. ${ }^{10}$ All cases of intermittent exotropia of divergence excess type may not have been detected, as most fixation tasks are carried out at near fixation in this age group.

In a recent study of vision screening tests applied by health visitors to high risk infants under the age of 2 years almost all the children who were identified as having a heterotropia had an obvious defect on direct observation. ${ }^{11}$

Low birth weight infants and infants admitted to a special care nursery have a higher prevalence of cerebral palsy than the remainder of the infant population. ${ }^{12}$ Eye defects are frequently present in children with cerebral palsy, ${ }^{13}$ and indeed such defects accounted for almost half of all eye defects seen in the high risk group. Eye examination of all children with a central motor deficit would appear to be indicated. Conversely, the presence of a heterotropia in a low birth weight infant may be a marker of an underlying motor deficit.

Amblyopia was not included in our classification of defects, as the diagnosis could not be confidently made in this very young age group..$^{14}$ Accurate testing of uniocular visual acuity was not possible before the age of 2 years with the equipment available in the clinics. However, a number of children with strabismus and anisometropia as well as those with conditions such as lens opacities and ptosis, were under observation, or receiving treatment for potential or suspected amblyopia. They are classified within other groups as appropriate.

At the time of this study there was no systematic ophthalmological follow-up exam- 
Range of refractive errors: High risk group

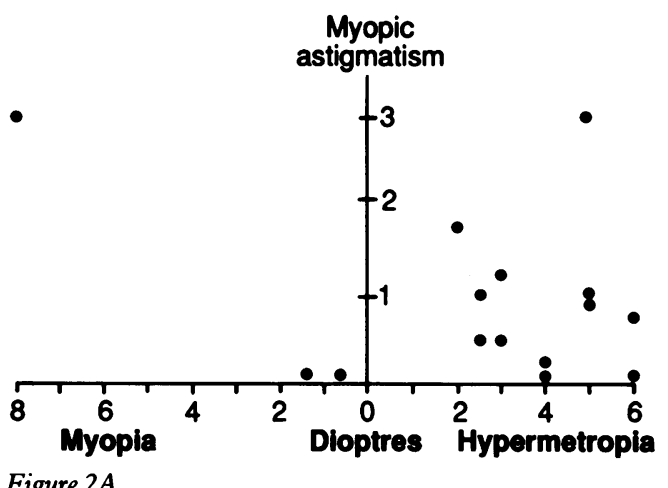

Figure 2A

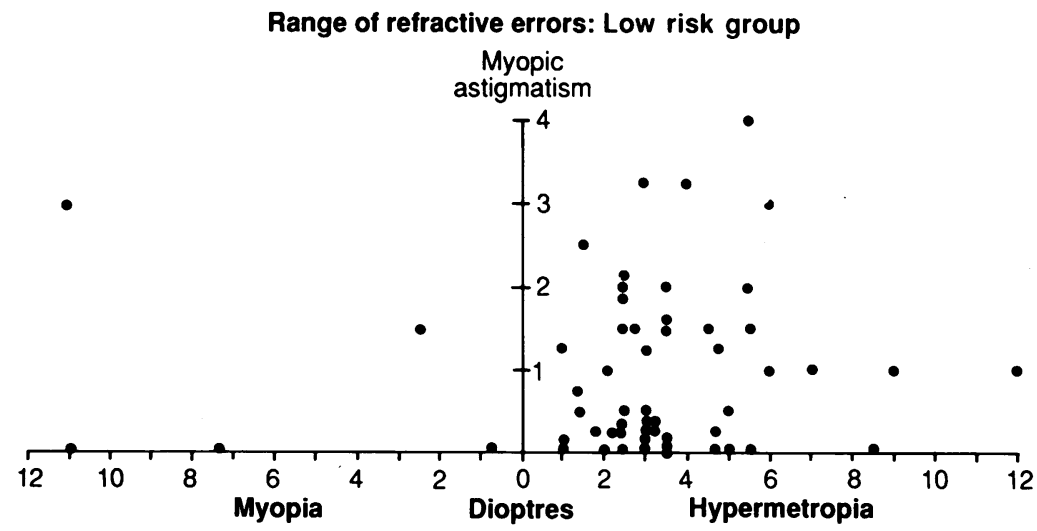

Figure 2B

Figure 2: Range of refractive errors in high risk and low risk groups. (Eye with highest refractive error recorded). high in infants who have been of low birth weight or been admitted to a special care nursery, these infants will form only a small proportion of all defects seen by the ophthalmic services by the age of 2 years. Yet their disability is often severe and associated with other deficits especially in the motor area. Hence the demands they make on clinical services are considerable.

It is possible that in future the numbers of impaired infants in the high risk group may increase. It is likely that, with neonatal intensive care, mortality rate among the high risk infants will continue to fall, and it is arguable that as more of the vulnerable high risk infants survive the numbers of children with a vision or ocular defect will increase. A counter-argument is that the increasing sophistication of neonatal intensive care will in the future result in not only a continuing fall in mortality rate but also an improving quality of survivors. These two opposing views are at present largely unsubstantiated, and as the limits of viability continue to be lowered it will be essential to monitor trends in numbers and characteristics of ocular and visual defects seen in the early childhood population.

We thank Ms Alison Macfarlane for statistical advice, and Miss Rosemary King and Mrs Olive Goddard for help with preparation of the manuscript.

We are grateful to the staff of orthoptic clinics, especially in Horton General Hospital, Banbury and Wallingford Community Hospital, and the staff of medical records departments throughout the district, for their assistance with this study.

Funds for this study were provided by Oxfordshire Health Authority (Locally Organised Research Grant). The Oxford Region Child Development Project is funded jointly by the Department of Health and the Oxford Regional Health Authority.

1 Macfarlane A, Mugford M. Birth counts. Statistics of pregnancy and childbirth. London: HMSO, 1984.

2 Hungerford J, Stewart A, Hope P. Ocular sequelae of preterm birth and their relation to ultrasound evidence of cerebral birth and their relation to ultrasound evider

ination of infants who had been in the Special Care Baby Unit, and hence milder grades of retinopathy of prematurity were not consistently reported. A system of regular evaluation of all such infants is now operating, and it is likely that this will result in an increase in the number of high risk infants requiring ongoing surveillance by specialist ophthalmological services.

Not all children had a recorded refractive error, but the overall impression was that the range of refractive errors did not differ between the high risk and low risk groups. In particular we were unable to demonstrate a high prevalence of myopia (possibly as a feature of retinopathy of prematurity) in the low birth weight population as has been previously described. ${ }^{813}$ However, without a systematic follow-up of the ocular status of the low birth weight infants it is likely that some children with myopia will only become known to the ophthalmological services after the age of 2 years.

Overall, we conclude that, although the relative risk of ocular or visual impairment is

3 Keith CG, Kitchen WH. Ocular morbidity in infants of very low birth weight. BrF Ophthalmol 1983; 67: 302-5.

4 Johnson A. Screening tests for hearing and vision impairment. How and when are they done? Health Visitor 1986; 59: $140-2$

5 Office of Population Censuses and Surveys. Key population and vital statistics. Series VS 15, no. 11. London: HMSO, 1988.

6 Kendall JA, Stayte MA, Wortham C. Ocular defects in children from birth to 6 years of age. Br Orthopt $\mathcal{f} 1989 ; 46$ : 3-6.

7 Kohler L. Health control of 4 year old children. An epidemiological study of child health. Acta Paediatr Scand (Suppl) 1973; 62: 17 .

8 Kushner BJ. Strabismus and amblyopia associated with regressed retinopathy of prematurity. Arch Ophthalmol 1982; 100: 256-61.

9 Friedman Z, Neumann E, Hyams SW, Peleg B. Ophthalmic screening of 38000 children, age 1 to $2 \frac{1}{2}$ years, in child welfare clinics. $\mathcal{F}$ Pediatr Ophthalmol Strabismus 1980; 17 261-7.

10 Burian HM, Von Noordon GK. Binocular vision and ocula motility. 3rd ed. St Louis: Mosby, 1985: 5: 92.

11 Johnson A, Stayte MA, Wortham C. Vision screening at age 8 months and 18 months. $\mathrm{Br}$ Med F 1989; 299: 545-9.

12 Johnson A, King R. A regional register of early childhood impairments - a discussion paper. Community Med 1989; 11 : 352-63.

13 Black P. Visual disorders associated with cerebral palsy. $\mathrm{Br} \mathcal{F}$ Ophthalmol 1982; 66: 46-52.

14 Shaw DE, Minshull C, Fielder AR, Rosenthal AR. Amblyopia - factors influencing age of presentation. Lancet 1988; ii: $207-9$. 